Natalia Xunaaxy Silva Delgado 


\section{Revisión del argumento reidiano sobre la justificación del testimonio}

\section{Introducción}

Durante mucho tiempo la epistemología - rama de la filosofía que estudia lo referente al conocimiento y a la creencia justificada- había tenido un enfoque principalmente individualista, es decir, se centraba más que nada en las actitudes doxásticas de los individuos, abstrayéndolos de esta forma de su entorno social. No obstante, la situación epistémica humana no es meramente individual, pues está conformada en gran medida por las relaciones sociales. La epistemología social surge entonces como una rama de la epistemología, encargada de investigar los efectos epistémicos de las interacciones sociales y las propiedades epistémicas de los individuos que surgen de sus relaciones con los demás. ${ }^{1}$

\section{El testimonio}

Con este nuevo enfoque en la epistemología se estudiaron nuevas fuentes epistémicas, es decir, formas en que podemos adquirir conocimientos o creencias justificadas. Las fuentes epistémicas estándar en la epistemología tradicional individualista son la percepción, la introspección, la memoria, la reflexión, el razonamiento deductivo e inductivo, etcétera. Pero al abrir el camino al estudio de las relaciones epistémicas interpersonales aparece un nuevo tipo de fuente a considerar, a saber, el testimonio. ${ }^{2}$

Mucho de lo que sabemos y de las creencias que tenemos se originan a partir de los reportes de otras personas. El conocimiento

1 Cfr. Goldman, A., y Blanchard, T., Social Epistemology, en Stanford Encyclopedia of Philosophy, Ed. Stanford University, EUA, 2016, disponible en: https://plato.stanford.edu/entries/epistemology-social/

2 Idem. 
o la justificación de una creencia se pueden adquirir al escuchar lo que otros dicen o al leer lo que escriben. Por ejemplo, sé sobre muchos de los hechos del pasado no porque los haya experimentado yo misma, sino por vía testimonial. Asimismo, he formado creencias a partir del testimonio sobre muchos de los asuntos de los cuales no soy experta. El testimonio es, quizás, una de las vías más importantes y más frecuentemente utilizadas para la formación de creencias y adquisición de conocimiento.

Nuestra dependencia del testimonio es tan profunda como omnipresente. Nos basamos en los informes de otros para nuestras creencias sobre los alimentos que comemos, el medicamento que ingerimos, los productos que compramos, la geografía del mundo, los descubrimientos en ciencia, información histórica y muchas otras áreas que juegan un papel crucial tanto en nuestra vida práctica y nuestra vida intelectual. Incluso muchas de nuestras creencias más importantes acerca de nosotros mismos fueron aprendidas, en una etapa temprana, de nuestros padres y cuidadores, tales como la fecha de nuestro nacimiento, la identidad de nuestros padres, nuestros orígenes étnicos, etc. Si tuviéramos que abstenernos de aceptar el testimonio de otros, nuestras vidas se verían empobrecidas de maneras sorprendentes y debilitantes. ${ }^{3}$

El testimonio es, entonces, una fuente epistémica, fruto de la interacción con otras personas, mediante la cual obtenemos o formamos creencias y conocimiento a partir de los reportes que hacen tales personas con el fin de compartir información. Esta fuente se distingue de las demás fuentes ya mencionadas porque no resulta de una experiencia directa, sino de la emisión de un hablante -la cual escuchamos o leemos.

Para poder saber a qué nos referimos con el término testimonio, cabe preguntarnos cuáles son las características que deben tener dichos reportes emitidos por los demás para poder considerarlos como fructíferos epistémicamente y ser catalogados como testimonios.

En su artículo ¿Qué es testimonio?, Peter J. Graham brinda una serie de condiciones para que algo sea considerado como tes-

3 Lackey, J. y Sosa, E., The epistemology of testimony, Oxford University Press, EUA, 2006, p. 1. 
timonio argumentando que un hablante $S$ testifica al hacer alguna declaración $p$ si y sólo si:

G1. La declaración de $S$ de $p$ es ofrecida como evidencia de que $p$.

G2. S intenta que su audiencia crea que él tiene la competencia relevante, autoridad o credenciales para declarar verdaderamente que $p$.

G3. La declaración de $S$ de que $p$ es considerada por $S$ como relevante para algún problema que cree es discutido o está irresuelto (que puede o no ser $p$ ) y está dirigido a aquellos en los que él cree que necesitan evidencia sobre el asunto. ${ }^{4}$

Por otro lado, Lackey ofrece una caracterización aproximada del testimonio resaltando la importancia de la noción de transmitir información. Para ella, una adecuada cuenta del testimonio debe reconocer la distinción entre expresiones de pensamiento no informacionales y testimonio. La caracterización que ofrece es la siguiente:

T: $S$ testifica que $p$ haciendo un acto de comunicación a si y sólo si (en parte) en virtud del contenido comunicable de a (1) $S$ razonablemente tiene la intención de transmitir información o (2) a es razonablemente considerado como transmisor de la información de que $p .5$

Considerando ambas posturas, podemos distinguir aspectos fundamentales para que algo sea testimonio: que sea una declaración ofrecida como evidencia, que difunda conocimiento a través de la comunicación y que tenga la intención de transmitir información.

Ahora bien, hemos visto que recurrimos a las experiencias, declaraciones o aserciones de otros y a partir de ellas formamos creencias. Gracias al testimonio es posible la reunión, producción y difusión de conocimientos. Se reconoce su omnipresencia y ubicuidad. Nuestro conocimiento depende en gran medida de

4 Graham, P, What is testimony?, The Philosophical Quarterly, 47, 1997, pp. 227-232.

5 Lackey, J. y Sosa, op. cit., p. 3. 
él. ¿Pero en qué casos estamos o no justificados para creer en él? $¿$ ¿Cómo podemos justificar las creencias que se originan testimonialmente?

\section{La justificación del testimonio}

Con respecto al problema de la justificación del testimonio hay, en general, dos grandes posturas que muchos han considerado antagónicas: el reduccionismo y el antirreduccionismo ${ }^{6}$. A grandes rasgos, la primera postura establece como una condición necesaria para justificar nuestras creencias testimoniales que el testimonio pueda ser reducido a alguna otra fuente de justificación epistémica.

Esta postura se ha asociado generalmente con el filósofo escocés del siglo XVIII David Hume, a quien se considera como una de las figuras principales e inaugurales del reduccionismo. Según Hume "no hay un tipo de razonamiento más común, más útil o incluso más necesario para la vida humana que el derivado de los testimonios de los hombres y los informes de los testigos presenciales y de los espectadores" ${ }^{\prime \prime}$ y acerca de nuestra confianza y seguridad que concedemos a argumentos de esa clase apunta que "no deriva de ningún otro principio que la observación de la veracidad del testimonio humano y de la habitual conformidad de los hechos con los informes de los testigos".

Así, según el razonamiento de Hume, el testimonio se justifica mediante un razonamiento inductivo: podemos confiar en los reportes de otras personas gracias a la observación directa del éxito testimonial pasado, basado en la conjunción constante de la concordancia de los reportes testimoniales con los hechos.

Por otro lado está el antirreduccionismo, cuyas raíces históricas se asocian al filósofo escocés contemporáneo de David Hume, Thomas Reid. Los antirreduccionistas defienden el testimonio como una fuente primitiva de conocimiento, tan fundamental como cualquier otra fuente directa, por lo que sugieren que

6 Páez, A., La prueba testimonial y la epistemología del testimonio, Isonomía, 40, 2014, pp. 95-118.

7 Hume, D., Investigación sobre el conocimiento bumano, Ed. Altaya, España, 1994, p. 135.

8 Idem. 
la actitud epistémica más adecuada es la de confiar en él a no ser que haya buenos motivos para no hacerlo. "El antirreduccionismo [... ] surge de la observación de la forma en que utilizamos la información testimonial en la vida cotidiana. La gran mayoría de nuestras creencias han sido adquiridas a partir de las palabras de los demás, sin que nos detengamos a pensar en la confiabilidad de la fuente"

El testimonio para ellos es una fuente tan básica de justificación como la percepción, la memoria, la inferencia y similares. "En consecuencia, en tanto que no haya socavadores, los oyentes pueden justificadamente aceptar las aserciones de los hablantes simplemente sobre la base del testimonio de un hablante"10.

\section{Reid y el testimonio}

Acerca de la postura que Reid mantiene sobre cuándo y por qué confiar en el testimonio, ésta se basa en dos principios relacionados con la idea de que Dios nos creó con la intención de que fuésemos criaturas sociales. Según Reid, Dios nos implantó dos principios con esta finalidad, el principio de veracidad y el principio de credulidad. Reid dice:

El sabio y benefactor Autor de la naturaleza, que pretendió que fuésemos criaturas sociales y que recibiésemos la mayor y más importante parte de nuestro conocimiento por medio de la información de otros, ha implantado en nuestras naturalezas, para estos propósitos dos principios que concuerdan el uno con el otro. El primero de estos principios es una propensión a decir la verdad, y a emplear los signos del lenguaje para transmitir nuestros verdaderos pensamientos [...] Otro principio original implantado en nosotros por el Ser supremo es una tendencia a confiar en la veracidad de los demás y a creer lo que nos dicen. Éste complementa al otro; $y$ al igual que aquél puede llamarse el principio de veracidad, llamaremos a este principio [... el el principio de credulidad. ${ }^{11}$

9 Páez, A., op. cit., p. 98.

10 Lackey, J. y Sosa, op. cit., p 4.

11 Reid, T., Investigación sobre la mente bumana según los principios del sentido común, Trotta, España, 2004, pp. 267-268. 
Según él, los seres humanos tenemos una "credulidad natural", una disposición instintiva a creer en lo que otros dicen y en su veracidad, mucho antes de tener la idea de mentira o de pensar en la posibilidad de ser engañados, así como también tenemos la propensión a decir la verdad.

Para Reid, cualquier afirmación es solvente hasta que se demuestre lo contrario. El mismo dice:

Es evidente que, en materia del testimonio, la balanza del juicio humano está por naturaleza inclinada hacia el lado de la creencia; y se inclina hacia ese lado cuando no hay nada que poner en el otro. Si no fuese así, no se creería ninguna proposición pronunciada y juzgada por la razón; y la mayoría de los hombres serían incapaces de encontrar razones para creer ni una milésima parte de lo que se les dijese. Tal desconfianza e incredulidad nos situaría en una situación peor que la de los salvajes ${ }^{12}$.

Pero tampoco es que esta credulidad sea o implique ingenuidad. El principio de credulidad, según Reid, es ilimitado en la infancia, y a medida que crecemos se ve poco a poco restringido $y$ regulado. Nuestra confianza en el testimonio es inicialmente instintiva y se ve regulada a medida que maduramos.

Muchas veces confiamos en el testimonio de forma natural, como él dice, y no erramos al hacerlo, como cuando solicitamos indicaciones a un desconocido para poder llegar a una dirección, atendemos a lo que nos dice, formamos creencias a partir de su testimonio y no nos detenemos a pensar si nos está mintiendo o no; asimismo, cuando un médico nos dice que tenemos cierto padecimiento y debemos tomar tal medicamento, formamos una creencia y actuamos a partir de su testimonio sin siquiera considerar la posibilidad del engaño.

En este sentido, parece que Reid tiene razón al afirmar que si no estuviéramos dispuestos a creer y examináramos minuciosamente la información dada por el testimonio, no podríamos encontrar razones para creer la milésima parte de lo que se nos dijo. No es posible que vivamos con tanta desconfianza e incredulidad. Sin embargo, ser criaturas sociales propensas a decir la verdad y tener una disposición a confiar y creer lo que los otros nos dicen no son condiciones

12 Ibidem p. 268. 
suficientes para confiar en el testimonio y es en este sentido que la postura de Reid no nos protege de los falsos testimonios.

A pesar de que nuestra confianza y credulidad se ven reguladas a medida que maduramos, seguimos siendo engañados. La gente miente, a veces los testimonios son falsos, no podemos apelar siempre al principio de veracidad, pues el que seamos propensos a decir la verdad no implica que no haya casos en los que no lo hagamos.

Thomas Reid no ignoraba esto. Él afirma que por el instinto de decir la verdad:

Se forma una conexión real entre nuestras palabras y nuestros pensamientos, y, así, las primeras se capacitan para convertirse en signos de los últimos [...] Y aunque esta conexión se rompe en cada caso de mentira y equivocación, sin embargo, estos casos, al ser comparativamente escasos, sólo debilitan pero no destruyen la autoridad del testimonio humano ${ }^{13}$.

Además, si consideramos las nuevas teorías en biología evolutiva y sociobiología sobre la cooperación y el altruismo, la propuesta de Reid resulta ser bastante apropiada para explicar el fenómeno del testimonio desde esta óptica. Según las tesis generales sobre el altruismo, a pesar de un proceso evolutivo que está centrado en la lucha por la vida,

los organismos no están necesariamente en un conflicto perpetuo con armas de ataque y defensa. En particular, la cooperación puede ser una buena estrategia biológica. También sabemos que los humanos son los organismos que de manera preeminente han adoptado esta vía de la cooperación y colaboración ${ }^{14}$.

Entre los organismos que se decidieron a aceptar el pastel compartido están los seres humanos. Los seres humanos utilizamos el altruismo biológico mucho más hábilmente que otros animales. Formamos estrechos lazos cooperativos que han permitido en última instancia la supervivencia de nuestra especie.

13 Idem.

14 Ruse, M., La significación de la evolución, en Compendio de Ética (pp. 667 680), Ed. Alianza, España, 2004, p. 670. 
A pesar de que se hable de altruismo biológico en términos de conducta, es decir, de cooperación y ayuda mutua entre los miembros de las especies por razones de utilidad biológica, podemos pensar que esta cooperación no podría llevarse a cabo sin que existiera cierto nivel de confianza entre dichos miembros. Ahora bien, específicamente en lo que se refiere a los seres humanos, la confianza es primordial para establecer lazos sociales que finalmente sean útiles para la propia supervivencia. Así, tal como lo decía Reid, la inclinación a decir la verdad y a creer en lo que los demás nos dicen es fundamental para poder ser seres sociales, si aceptamos que son condiciones necesarias para generar vínculos de confianza.

\section{Conclusión}

De esta forma, resulta interesante la posibilidad de considerar las nuevas teorías en biología evolutiva y sociobiología sobre la cooperación y el altruismo para reformular la propuesta de Reid desde esta óptica y explicar el fenómeno del testimonio y los principios que postula con un enfoque mucho más actual. 
